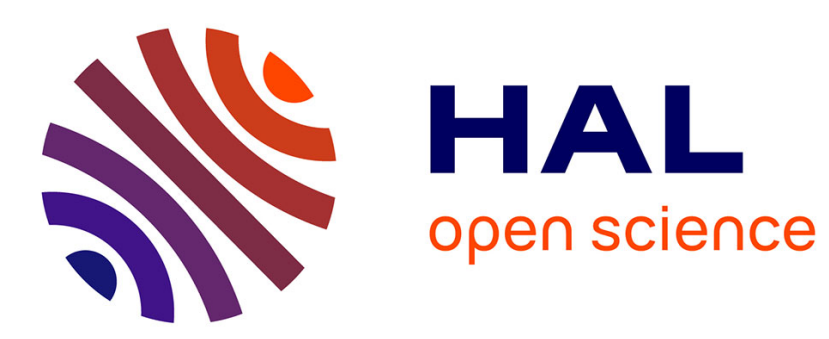

\title{
Characterization of adsorbates by transient measurements in Scanning Electrochemical Microscopy
}

Dao Trinh, Michel Keddam, Xosé Ramon Novoa, Vincent Vivier

\section{To cite this version:}

Dao Trinh, Michel Keddam, Xosé Ramon Novoa, Vincent Vivier. Characterization of adsorbates by transient measurements in Scanning Electrochemical Microscopy. Electrochimica Acta, 2014, 131, pp.28-35. 10.1016/j.electacta.2014.02.002 . hal-01020311

\section{HAL Id: hal-01020311 \\ https: / hal.sorbonne-universite.fr/hal-01020311}

Submitted on 18 Jul 2014

HAL is a multi-disciplinary open access archive for the deposit and dissemination of scientific research documents, whether they are published or not. The documents may come from teaching and research institutions in France or abroad, or from public or private research centers.
L'archive ouverte pluridisciplinaire HAL, est destinée au dépôt et à la diffusion de documents scientifiques de niveau recherche, publiés ou non, émanant des établissements d'enseignement et de recherche français ou étrangers, des laboratoires publics ou privés. 
1

\section{Characterization of adsorbates by transient measurements in Scanning Electrochemical Microscopy}

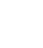
Dao TRINH ${ }^{a, b, t, 1}$, Michel KEDDAM ${ }^{a, b}$, Xosé Ramón NÓVOA ${ }^{c, 1}$, and Vincent VIVIER ${ }^{a, b, 1, *}$

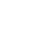

${ }^{a}$ CNRS, UPR15, Laboratoire Interfaces et Systèmes Electrochimiques, F-75005 Paris, France

${ }^{b}$ UPMC Université P. et M. Curie, UPR15, LISE, 4 place Jussieu, F-75005 Paris, France

${ }^{c}$ ENCOMAT group, E.E.I, Universidade de Vigo, Campus Universitario, 36310 Vigo, Spain.

\footnotetext{
${ }^{1}$ ISE member

† Present address: Université de la Rochelle, Laboratoire des Sciences de l'Ingénieur pour l'Environnement, F-17000 La Rochelle, France

*Corresponding author: $\quad$ vincent.vivier@upmc.fr

䀂 $+33(0) 144274158$
} 


\section{Abstract}

In this work, we demonstrate that the use of the scanning electrochemical microscopy in transient mode allows the investigation of adsorbate intermediates at a polarized interface. Two different systems were studied. In the case of a competitive adsorption involving halide and hydrogen, the contribution of each element was monitored independently. Interestingly, the simultaneous measurement of the electrochemical impedance allowed the complex differential capacitance for each adsorbed species to be calculated. In the case of the iron dissolution, the formation of a monovalent Fe species was evidenced allowing to discriminate between different dissolution mechanisms previously described in the literature.

Keywords: Scanning Electrochemical Microscopy; AC-SECM; Adsorbate intermediate; Competitive adsorption; Electrochemical impedance spectroscopy. 


\section{Introduction}

Electrochemical impedance spectroscopy, EIS, has been widely used for investigating complex electrochemical mechanisms such as those involved in corrosion or metal dissolution [1-5]. When combined with one or more other potential-modulation based techniques, it allows multiple transfer functions to be determined offering the possibility of gathering simultaneously various type of data. For instance, the kinetics and the exchange of ions and molecules inside a thin polymer film has been investigated using ac-electrogravimetry method [6-8], whereas the use of a double-excitation technique allowed the investigation of the double layer relaxation [9-11].

It has also been shown that the rotating ring-disk electrode (RRDE) allows the investigation of electrochemical and coupled chemical reactions [12-14]. In their pioneering work, the group of Albery has used the alternating current measurements for defining a complex collection efficiency as the ratio of the ac-current collected at the ring to the ac-current generated at the disk [15-17]. This approach was successfully used for characterizing the formation of thin films at an electrode surface [18, 19], and was extended to channel flow double electrode for the study of the iron dissolution [20].

Scanning electrochemical microscopy (SECM) also allows the investigation of the electrochemical interface using a microelectrode as a collecting electrode [21, 22]. SECM has been successfully used to investigate intricate systems such as those encountered in corrosion [23-29], for performing the dosing of adsorbed intermediates (electro)generated on a substrate using the surface interrogation mode (SI-SECM) [3032]. Recently, Trinh et al. [33, 34] have shown that a transient SECM (similarly to what has been done for the RRDE) allowed a quantitative study of adsorption processes. 
1 It is generally difficult to identify intermediate species involved in multistep reactions. For instance, halide and hydrogen adsorption have a competitive character [35-37] and various mechanisms involved in corrosion refer to the formation of adsorbates or thin films $[1,2,19]$.

In this paper, we report on possibility of studying elementary steps by transient SECM. Two different examples are presented: the reduction of proton on a polycrystalline Pt electrode compared with the competitive adsorption of bromide ions and the dissolution of iron in acidic solution. In both cases, the mechanisms are assumed to involve adsorbate intermediates.

\section{Experimental}

\subsection{Experimental setup}

All experiments were performed with a homemade SECM device already described elsewhere [38, 39]. Briefly, it consisted in a 3-axis positioning system (VP-25XA, Newport) driven by a motion encoder (ESP300, Newport) allowing a 3-axis displacement with a $100 \mathrm{~nm}$ resolution. The electrochemical measurements were performed with a homemade bi-potentiostat coupled to a low noise current-to-voltage transducer (Femto DLPCA200, BFI Optilas) with adjustable gain $\left(10^{3}-10^{11} \mathrm{~V} / \mathrm{A}\right)$. Current and potential measurements were performed with an AD/DA card (PCI-6281 - National Instruments), and the whole experimental device is controlled by a homemade software allowing usual SECM experiment to be achieved, but also multiple transfer functions to be obtained from the different input channels of the data acquisition card. A four-electrode 
configuration ( 2 working electrodes, one reference electrode, and one counter electrode) was used as described previously [33, 34].

\subsection{Materials and Reagents}

Microelectrodes were made from 10 and $40 \mu \mathrm{m}$-diameter platinum wires, sealed in a glass capillary by using a microforge. A polycrystalline platinum electrode of $5 \mathrm{~mm}$ in diameter isolated by an epoxy resin was used as substrate.

All solutions were prepared in distilled water from analytical-grade chemicals. A $0.5 \mathrm{M}$ $\mathrm{H}_{2} \mathrm{SO}_{4}$ solution was used for the study of the proton reduction and the adsorption of hydrogen on polycrystalline platinum electrode. In order to study the competitive adsorption between hydrogen and bromine on platinum, a mixture of $0.1 \mathrm{M} \mathrm{HClO}_{4}$ and 5 $\mathrm{mM} \mathrm{KBr}$ was used. Prior to the experiments, Pt electrodes were cleaned by performing repetitive scans over one hour between the HER and the OER reaction in sulfuric acid solution.

The iron used in this study was a massive high-purity iron (99.99\%) purchased from Johnson-Matthey. It was firstly annealed during $4 \mathrm{~h}$ at $995^{\circ} \mathrm{C}$ in vacuum and then quenched in water. The rod was laterally insulated with a cataphoretic paint and embedded in an epoxy resin. Prior to each experiment, the electrode was polished with $\mathrm{SiC}$ paper down to grade 2400, cleaned in water in an ultrasonic bath and then dried with warm air. The anodic dissolution of iron was investigated in $0.5 \mathrm{M} \mathrm{H}_{2} \mathrm{SO}_{4}$ solution.

\subsection{SECM measurements}

The dimensionless size of the microelectrode tip $R G\left(R G=r_{g} / a\right.$, where $r_{g}$ is the total external diameter of the microelectrode and $a$ the disc microelectrode radius) and the 
dimensionless tip-to-substrate distance $L(L=d / a$ where $d$ is the actual tip-to-subtrate distance) were determined by performing approach curves in negative feedback mode. The SECM experiments in transient mode and the electrochemical impedance spectroscopy were performed under potentiostatic regulation of the substrate with a $50 \mathrm{mV}$ peak-to-peak sine wave perturbation signal. This amplitude was chosen to improve the signal-to-noise ratio, while the linearity condition for the electrochemical system is maintained. The frequency was varied from $10 \mathrm{kHz}$ down to $50 \mathrm{mHz}$ with 7 frequencies per decade.

\section{Basic of the transient SECM measurements}

The transient technique used in this study is based on the former works of Albery et al. [12-14] and Benzekri et al. [18, 19] devised for rotating ring-disk electrode. In generator/collector mode, an obvious analogy exists between the SECM and the RRDE: redox species generated at one electrode can be detected at the second electrode, the timeof-flight being governed by the distance between the probe and the substrate of the SECM experiment, and by the rotation rate and the interelectrode distance in the case of the RRDE. In addition, the collection efficiency can be defined as the ratio of the current of the collecting electrode to that of the generating one. Similar to a usual electrochemical impedance measurement, a small sine-wave perturbation can be superimposed to the dc component of the substrate (at steady-state), allowing the complex transfer function $N(\omega)$ corresponding to the complex collection efficiency to be defined as:

$$
N(\omega)=\frac{\Delta I_{\text {tip }}(\omega)}{\Delta I_{\text {sub }}(\omega)}
$$


where $\Delta I_{\text {tip }}(\omega)$ and $\Delta I_{\text {sub }}(\omega)$ are the ac-components of the tip and substrate currents, respectively. The introduction of the electrochemical fluxes at the substrate, $\Delta \Phi_{\text {sub }}(\omega)$, and at the tip, $\Delta \Phi_{\text {tip }}(\omega)$, in Eq.(1) allows the rewriting of $N(\omega)$ as:

$$
N(\omega)=\frac{\Delta I_{\text {tip }}(\omega)}{\Delta \Phi_{\text {tip }}(\omega)} \cdot \frac{\Delta \Phi_{\text {tip }}(\omega)}{\Delta \Phi_{\text {sub }}(\omega)} \cdot \frac{\Delta \Phi_{\text {sub }}(\omega)}{\Delta I_{\text {sub }}(\omega)}
$$

In the right hand-side of Eq.(2), the first term is the inverse of the complex collection efficiency on the tip, $N_{\text {tip }}(\omega)=\frac{\Delta \Phi_{\text {tip }}(\omega)}{\Delta I_{\text {tip }}(\omega)}$. For this technique, a simple redox reaction has to be chosen on the tip (i.e. a kinetically fast electrochemical reaction non complicated by any coupled chemical reaction) in order to maintain its value frequency independent.

The second term is the complex transport coefficient, $N_{t}(\omega)=\frac{\Delta \Phi_{\text {tip }}(\omega)}{\Delta \Phi_{\text {sub }}(\omega)}$, corresponding to the mass transport contribution of electroactive species between the substrate and the tip collector electrode. This contribution always exists and can be determined experimentally. Fig. 1 shows an example of the Nyquist representation of the complex collection efficiency measured for a SECM experiment when using ferricyanide as redox mediator. The potential of the Pt substrate was set at $0.465 \mathrm{~V} / \mathrm{SHE}$ and the Ptmicroelectrode (tip) was biased at $0.745 \mathrm{~V} / \mathrm{SHE}$ to oxidize the collected $\mathrm{Fe}^{2+}$ species. When an ac-perturbation was applied to the substrate, the ferrocyanide ions diffuse in solution and are detected at the tip. The shape of the curve (a semi-cardioid) is very similar to the curves obtained with the $\operatorname{RRDE}$ system $[18,19]$ or with a channel flow double electrode system [20]. The low frequency limit corresponds to the steady-state 
collection efficiency, whereas the high frequency limit was about $100 \mathrm{~Hz}$, which is larger than with other generator / collector systems and depends on the probe-to-substrate distance as expected [20]. At higher frequency, the small tail was ascribed to the ohmic coupling between the two working electrodes as already pointed out for a generator / collector system by Gabrielli et al. [40]. Thus, the collection response is similar to that of a low-pass filter $[18,20]$ and Trinh et al. have also shown that this contribution can be evaluated numerically by using finite element simulations [33].

\section{----- Figure 1 -----}

The last term in the right hand-side of Eq.(2) is the complex emission efficiency of the substrate, $N_{\text {sub }}(\omega)=\frac{\Delta \Phi_{\text {sub }}(\omega)}{\Delta I_{\text {sub }}(\omega)}$, which is the quantity of interest in this study. It can be calculated from the independent determination of both the complex collection efficiency and $N_{\text {sub }}(\omega)$. Further, if the double-layer charging is neglected, the non-steady-state current measured at the substrate is the sum of the flux of species released in solution, $\Delta \Phi_{\text {sub }}$, and of the Faradaic charge stored at the interface, $\Delta Q_{\text {sub }}$, corresponding to the formation of adsorbate intermediates or thin solid films:

$$
\Delta I_{\text {sub }}=n_{\text {sub }} F \Delta \Phi_{\text {sub }}+\frac{d \Delta Q_{\text {sub }}}{d t}
$$

where $n_{\text {sub }}$ is the number of electrons involved in the electrochemical reaction at the substrate, and $F$ the Faraday constant. In the frequency domain, Eq.(3) can be rewritten in dimensionless form as:

$$
n_{\text {sub }} F N_{\text {sub }}+j \omega \frac{\Delta Q_{\text {sub }}(\omega)}{\Delta I_{\text {sub }}(\omega)}=1
$$


In a Nyquist representation Eq.(4) corresponds to a semi circle in which $j \omega \frac{\Delta Q_{\text {sub }}(\omega)}{\Delta I_{\text {sub }}(\omega)}$ is the contribution of the charge exchanged for the formation of the adsorbates at the substrate. The high frequency limit of Eq.(4) corresponds to the kinetics of processes taking place at the substrate when controlled by the charge transfer resistance. Conversely, at the low frequency limit, the right hand-side term is null and the steadystate requires that the flux and the current are linked through the Faraday constant. The experimental setup used in this work allows the simultaneous measurement of the complex collection efficiency and the electrochemical impedance of the substrate, $Z_{\text {sub }}(\omega)$. Thus from Eq.(4), the differential capacitance of the substrate, $C_{d}$, can be then calculated as:

$C_{d}(\omega)=\frac{\Delta Q_{\text {sub }}(\omega)}{\Delta E_{\text {sub }}(\omega)}=\frac{1-n_{\text {sub }} F \Delta N_{\text {sub }}(\omega)}{j \omega Z_{\text {sub }}(\omega)}$ This provides a unique way of determining the relaxation ascribed to the charge stored at the interface during the electrochemical process. In the following section, this new technique will be used for the study of competitive adsorption between hydrogen and bromide ions on a Pt substrate and for the dissolution mechanism of iron. 


\section{Results and discussion}

\subsection{Competitive adsorption between $\mathrm{Br}_{\mathrm{ads}}$ and $\mathrm{H}_{\mathrm{ads}}$}

Fig. 2a shows the schematic representation of a monolayer of adsorbed hydrogen on platinum. The charge accumulated by this monolayer has been previously estimated by transient SECM at about $212 \pm 12 \mu \mathrm{F} \mathrm{cm}^{-2}$ from the low frequency limit of the Nyquist plot of the differential capacitance [34].

\section{----- Figure 2 -----}

In the presence of bromide ion, the schematic representation of competitive adsorption between the bromine and hydrogen is presented in Fig. $2 b$.

Fig. 3 shows the cyclic voltammogram of the platinum substrate in a $5 \mathrm{mM} \mathrm{KBr}+0.1 \mathrm{M}$ $\mathrm{HClO}_{4}$ solution. This voltammetry curve can be used to highlight the following phenomena: the reduction of the proton at potential lower than $-0.005 \mathrm{~V} / \mathrm{SHE}$, the adsorption of hydrogen in the potential range between 0.045 and $0.260 \mathrm{~V} / \mathrm{SHE}$, oxidation of the bromide at its standard potential about 1.19 V/SHE (Eq.(6)), and adsorption of bromide ion at $0.135 \mathrm{~V} / \mathrm{SHE}$ (Eq.(7)). These values are in good agreement with literature data $[41,42]$

$$
\mathrm{Br}^{-} \rightleftarrows \mathrm{Br}_{\mathrm{ads}}+e^{-}
$$

Ferro et al. [41, 43] studied the competitive adsorption between bromine and hydrogen on polycrystalline platinum electrode by gradually adding bromide ions (from 0 to $100 \mathrm{mM}$ ) 
1 in a solution of $\mathrm{HClO}_{4}$. They showed that the presence of bromide significantly alters the adsorption of hydrogen that was attributed to the competitive adsorption of bromine through the following reaction:

$4 \quad \mathrm{Br}^{-}+\mathrm{Pt}+\mathrm{H}^{+} \rightarrow \mathrm{Pt}-\mathrm{Br}_{\mathrm{ads}}+\frac{1}{2} \mathrm{H}_{2}$

The presence of bromide significantly alters the adsorption of hydrogen resulting in the gradual disappearance of the adsorption/desorption peak at about $0.260 \mathrm{~V} / \mathrm{SHE}$. Concomitantly, the peak at $0.135 \mathrm{~V} / \mathrm{SHE}$ increases with the bromide ion concentration, which confirms the competitive adsorption of bromine and hydrogen.

In this case, the total exchanged charge involved through the competitive formation of the hydrogen and bromine absorbed layer is the sum of the charge required for the adsorption of each species, $\Delta Q_{\text {sub }}^{H}$ and $\Delta Q_{\text {sub }}^{B r}$, respectively.

$$
\Delta Q_{\text {sub }}=\Delta Q_{\text {sub }}^{H}+\Delta Q_{\text {sub }}^{B r}
$$

The potential corresponding to the adsorption reaction of bromine is very close to the adsorption potential of hydrogen and it is difficult to distinguish between these two phenomena by conventional electrochemical methods, especially on a single voltammogram. By performing the transient SECM measurements while detecting different species generated from the substrate, specific information about each adsorption process can be gathered and the competitive reaction between the adsorption of bromine and hydrogen can be selectively studied. 
Figure 4 shows the differential capacitance $\frac{\Delta Q_{\text {sub }}}{\Delta E_{\text {sub }}}$ calculated from the experimental complex collection efficiency according to Eq. (5) in the case of bromine and hydrogen adsorption. The transient SECM measurements were performed at $E_{\text {sub }}=1.19 \mathrm{~V} / \mathrm{SHE}$ for bromine and $E_{\text {sub }}=-0.005 \mathrm{~V} / \mathrm{SHE}$ for hydrogen. For electrode potential value lower than $-0.005 \mathrm{~V} / \mathrm{SHE}$, the HER occurs on the substrate to form dissolved hydrogen which is then captured and oxidized by the tip (the tip is biased at $0.645 \mathrm{~V} / \mathrm{SHE}$ ). This reaction involves adsorbed intermediate according to the Volmer - Tafel or Volmer - Heyrovsky mechanism.

At $1.19 \mathrm{~V} / \mathrm{SHE}, \mathrm{Br}^{-}$is oxidized to $\mathrm{Br}_{2}\left(\mathrm{Br}_{3}^{-}\right)$which is then detected at the tip (tip potential is maintained at $0.645 \mathrm{~V} / \mathrm{SHE}$ to reduce the $\mathrm{Br}_{2}$ generated at the substrate). In both cases, the HF limit tends towards 0 because in the frequency domain, the impedance is governed purely by the charge transfer resistance. The low frequency limit corresponds to the charge accumulation at the electrode surface, i.e., $1 \mathrm{mFcm}^{-2}$ for hydrogen and $1.2 \mathrm{mF}$ $\mathrm{mFcm}^{-2}$ for bromine (Table 1). The latter value corresponds to the accumulation of charge on the substrate associated with the competitive adsorption between $H_{a d s}$ and Thus, varying the electrode potential allows the different contribution of absorbed species to be evaluated and the sum of charges involved in the formation of $H_{a d s}$ and $B r_{a d s}$ is given by $\Delta Q_{\text {sub }}=\Delta Q_{\text {sub }}^{H}+\Delta Q_{\text {sub }}^{B r}=71+85=156 \mu \mathrm{C} \mathrm{cm}^{-2}$. This value $\left(156 \mu \mathrm{C} \mathrm{cm}^{-2}\right)$ is 
smaller than the one obtained for a monolayer of adsorbed hydrogen in the absence of bromide ions $\left(212 \mu \mathrm{C} \mathrm{cm}^{-2}\right)$ which confirms the hypothesis of competitive adsorption of bromide ions on the site occupied by hydrogen on platinum substrate. It should also be mentioned that because both electrodes (tip and substrate) are made from the same material and were prepared following the same experimental procedure (grinding, washing, electrochemical cleaning), the roughness factor for each electrode was assumed to be the same. This allows expecting that the complex collection efficiency to be independent of this roughness factor.

In addition, the time-constant for the relaxation of $H_{a d s}$ at the electrode surface without the bromide ion in solution is about $2 \mathrm{~Hz}$ [34]. This frequency points to a kinetics ten times faster than the value determined in presence of bromide ions (Figure 4). All the characteristic constants extracted from these experiments are reported in Table 1. This behavior indicates a change in the mechanism and kinetics of adsorption of hydrogen in presence of a competitive adsorption.

\subsection{Mechanism of iron dissolution in acidic solution}

The dissolution mechanism of iron in an acidic solution has been the topic of controversy [44]. Two different mechanisms were considered based on the interpretation of current potential curves and electrochemical impedance diagrams [44-46], in which adsorbed monovalent iron species act as an intermediate in the transfer of the first and second electrons of $\mathrm{Fe}$ (mechanism proposed by J. O'M. Bockris, et al. [45]) whereas Heusler [46] suggested that it acts as a catalyst in the dissolution of divalent Fe cations in acidic solutions. 
1 These two mechanisms can be summarized as follows:

2 Bockris' mechanism [45] is described by two successive and irreversible elementary

3 steps involving $F e_{a d s}^{I}$ as adsorbate intermediate:

$4 \quad \mathrm{Fe} \stackrel{k_{1}}{\longrightarrow} \mathrm{Fe}_{\text {ads }}^{I}+e^{-}$

$\mathrm{Fe}_{\text {ads }}^{I} \stackrel{k_{2}}{\longrightarrow} \mathrm{Fe}_{\text {sol }}^{I I}+e^{-}$

Thus, mass and charge balances can be expressed as

$7 \quad \beta \frac{d \theta}{d t}=k_{1}(1-\theta)-k_{2} \theta$

$8 \quad i_{\text {Sub }}=F\left(k_{1}(1-\theta)+k_{2} \theta\right)$

9 where $\theta$ is the fractional surface coverage of $F e_{a d s}^{I}$ and $\beta$ is the maximum of surface 10 concentration of adsorbate intermediate. The flux of electrogenerated species at the 11 substrate is then given by

12

$\Phi_{\text {Sub }}=k_{2} \theta$

13 At steady-state, the fractional surface coverage is given by

$14 \quad \bar{\theta}=\frac{k_{1}}{k_{1}+k_{2}}$

15 The impedance of the substrate is given by

16

$$
\frac{1}{Z_{\text {sub }}}=F\left[\left(b_{1}+b_{2}\right) k_{2} \bar{\theta}-\left(k_{1}-k_{2}\right) \frac{\left(b_{1}-b_{2}\right) k_{2} \bar{\theta}}{k_{1}+k_{2}+\beta j \omega}\right]
$$




$$
N_{\text {sub }}=\left(b_{2} k_{2} \bar{\theta}+k_{2} \frac{\left(b_{1}-b_{2}\right) k_{2} \bar{\theta}}{k_{1}+k_{2}+\beta j \omega}\right) \times Z_{\text {sub }}
$$

2 The mechanism proposed by Heusler [46] also involves $F e_{a d s}^{I}$ as adsorbate intermediate,

3 but the later acts as a catalyst:

4

$$
\mathrm{Fe} \underset{k_{-1}}{\stackrel{k_{1}}{\rightleftarrows}} \mathrm{Fe} e_{a d s}^{I}+e^{-}
$$

$$
\mathrm{Fe}+\mathrm{Fe}_{\text {ads }}^{I} \stackrel{k_{2}}{\longrightarrow} \mathrm{Fe}_{\text {ads }}^{I}+\mathrm{Fe}_{\text {sol }}^{I I}+2 e^{-}
$$

The mass and charge balances can then be expressed as

$7 \quad \beta \frac{d \theta}{d t}=k_{1}(1-\theta)-k_{-1} \theta$

$$
i_{\text {Sub }}=F\left(k_{1}(1-\theta)-k_{-1} \theta+2 k_{2} \theta\right)
$$

9 The flux of electrogenerated species at the substrate is also given by

$$
\Phi_{\text {sub }}=k_{2} \theta
$$

11 At steady-state, the fractional surface coverage is given by

12

$$
\bar{\theta}=\frac{k_{1}}{k_{1}+k_{-1}}
$$

$$
\frac{1}{Z_{\text {sub }}}=F\left[\left(b_{1}-b_{-1}\right) k_{-1} \bar{\theta}+2 k_{2} b_{2} \bar{\theta}-\left(k_{1}+k_{-1}-2 k_{2}\right) \frac{k_{-1}\left(b_{1}-b_{-1}\right) \bar{\theta}}{k_{1}+k_{-1}+\beta j \omega}\right]
$$


$1 \quad N_{\text {sub }}=\left(b_{2} k_{2} \bar{\theta}+k_{2} \frac{k_{-1}\left(b_{1}-b_{-1}\right) \bar{\theta}}{k_{1}+k_{-1}+\beta j \omega}\right) \times Z_{\text {sub }}$

Fig. 5 shows the experimental impedance diagrams measured at the onset of the dissolution peak of pure iron as a function of the electrode potential. In each case two loops are evidenced, a high frequency capacitive one corresponding to the double layer capacity-charge transfer resistance and a low frequency inductive one generated by the frequency response of the surface coverage by the adsorbed reaction intermediate. These diagrams are characterized by a decrease of the impedance (larger value of the dissolution current) and a shift of the characteristic frequency towards shorter time-constant as the potential increases for both loops. Assuming that electrochemical steps follow Tafel kinetics and using the linearized expression of the currents given by Eq.(13) and Eq.(21), it is possible to calculate the impedance response as shown in Fig. 6a for the Bockris' mechanism and Fig. 6b Heusler's mechanism. Independently of the kinetic constants used for the simulation, in both cases the shape of the impedance diagrams are very similar to those obtained experimentally. Both the amplitude and time-constants vary in the same way. It is thus difficult to decide which mechanism is the most suited.

Fig. 7 shows the calculated collection efficiency of the substrate using the same set of parameters as those used for the impedance diagrams presented in Fig. 6. Interestingly, a 
1 different behavior is observed. In the case of Bockris' mechanism, the collection 2 efficiency locus overlap in amplitude and a small frequency shift can be observed (Fig. 3 7a) whereas for Heusler's mechanism, the amplitude of the complex collection efficiency 4 is potential dependent (Fig. 7b). As the potential increases, the high frequency limit increases corresponding to a change of the kinetic process at the substrate under the assumption of vanishing variations of the superficial concentration.

Fig. 8 shows the experimental complex collection efficiency of the substrate measured simultaneously with the impedance diagrams presented in Fig. 5. The shape of the transfer function does not depend on the potential and a small frequency shift is observed. These results compare favorably with the theoretical curves presented in Fig. 7a indicating that the Bockris' mechanism allows a quantitative description of the iron dissolution valid at low current densities and low $\mathrm{pH}[1,2]$. Thus the transient SECM allows distinguishing between different possible mechanisms. It should be mentioned that for experiments performed at higher potentials (thus for larger steady-state dissolution current), no reliable results could have been obtained. This was ascribed to the fact that under high dissolution rates the distance between the Pt-probe and the iron substrate varies too quickly compared to the time-scale of the impedance acquisition rate.

\section{Conclusions}

In this work, we have highlighted different intakes that can be obtained using the SECM

21 in transient mode in order to characterize an electrified interface. 
1 In the case of competitive adsorption between halide ions and hydrogen, it was shown that it is possible to discriminate between the different species and to evaluate independently the charge exchanged for each adsorbate.

4 In the case of the formation of an adsorbate intermediates like Fe(I) species, the complex collection efficiency of the substrate can decide between different mechanisms and appears to be a complementary approach to the usual impedance measurements.

The perspectives of this work are the investigation of reaction mechanism on well oriented materials such as the absorption and the competitive adsorption on single crystals and the investigation of the passive film formation and passive film reactivity as a function of the grain orientation.

\section{Acknowledgements}

The authors gratefully acknowledge D. Rose (UPR15) for technical support. 


\section{References}

[1] M. Keddam, O.R. Mattos, H. Takenouti, Reaction model for iron dissolution studied by electrode impedance. II. Determination of the reaction model, J. Electrochem. Soc., 128 (1981) 266-274.

[2] M. Keddam, O.R. Mattos, H. Takenouti, Reaction model for iron dissolution studied by electrode impedance. I. Experimental results and reaction model, J. Electrochem. Soc., 128 (1981) 257-266.

[3] I. Epelboin, C. Gabrielli, M. Keddam, H. Takenouti, Model of the anodic behavior of iron in sulfuric acid medium, Electrochim. Acta, 20 (1975) 913-916.

[4] C. Cachet, F. Ganne, G. Maurin, J. Petitjean, V. Vivier, R. Wiart, EIS investigation of zinc dissolution in aerated sulfate medium. Part I: bulk zinc, Electrochim. Acta, 47 (2001) $509-518$.

[5] C. Cachet, F. Ganne, S. Joiret, G. Maurin, J. Petitjean, V. Vivier, R. Wiart, EIS investigation of zinc dissolution in aerated sulphate medium. Part II: zinc coatings, Electrochim. Acta, 47 (2002) 3409-3422.

[6] C. Gabrielli, M. Keddam, N. Nadi, H. Perrot, a.c. Electrogravimetry on conducting polymers. Application to polyaniline, Electrochim. Acta, 44 (1999) 2095-2103.

[7] J. Agrisuelas, C. Gabrielli, J.J. García-Jareño, H. Perrot, F. Vicente, Kinetic and Mechanistic Aspects of a Poly(o-Toluidine)-Modified Gold Electrode. 2. Alternating Current Electrogravimetry Study in H2SO4 Solutions, J. Phys. Chem. C, 116 (2012) 15630-15640. 
[8] T.K.L. To, C. Debiemme-Chouvy, C. Gabrielli, H. Perrot, Redox Switching of Heteropolyanions Entrapped in Polypyrrole Films Investigated by ac Electrogravimetry, Langmuir, 28 (2012) 13746-13757.

[9] R. Antano-Lopez, M. Keddam, H. Takenouti, A new experimental approach to the time-constants of electrochemical impedance: frequency response of the double layer capacitance, Electrochim. Acta, 46 (2001) 3611-3617.

[10] R. Antano-Lopez, M. Keddam, H. Takenouti, Interface capacitance at mercury and iron electrodes in the presence of organic compound, Corros. Eng., Sci. Technol., 39 (2004) 59-64.

[11] E.R. Larios-Duran, R. Antano-Lopez, M. Keddam, Y. Meas, H. Takenouti, V. Vivier, Dynamics of double-layer by AC Modulation of the Interfacial Capacitance and Associated Transfer Functions, Electrochim. Acta, 55 (2010) 6292-6298.

[12] W.J. Albery, S. Bruckenstein, Ring-disk electrodes. VII. Homogeneous and heterogeneous kinetics, Trans. Faraday Soc., 62 (1966) 2596-2606.

[13] W.J. Albery, S. Bruckenstein, Ring-disk electrodes. V. First-order kinetic collection efficiencies at the ring electrode, Trans. Faraday Soc., 62 (1966) 1946-1954.

[14] W.J. Albery, S. Bruckenstein, Ring-disk electrodes. II. Theoretical and experimental collection efficiencies, Trans. Faraday Soc., 62 (1966) 1920-1931.

[15] S. Bruckenstein, K. Tokuda, W.J. Albery, Ring-disk electrodes. Part 17. Ring response to periodic disk electrode forcing functions, J. Chem. Soc, Farad. T. 1, 73 (1977) 823-829.

[16] W.J. Albery, R.G. Compton, A.R. Hillman, Ring-disk electrodes. Part 18. Collection efficiency for high frequency a.c, J. Chem. Soc, Farad. T. 1, 74 (1978) 1007-1019. 
[17] W.J. Albery, A.R. Hillman, Ring-disk electrodes. Part 19. Adsorption studies at low frequency a.c, J. Chem. Soc, Farad. T. 1, 75 (1979) 1623-1634.

[18] N. Benzekri, M. Keddam, H. Takenouti, The a.c. response of a rotating ring-disk electrode: application to 2-D and 3-D film formation in anodic processes, Electrochim. Acta, 34 (1989) 1159-1166.

[19] N. Benzekri, R. Carranza, M. Keddam, H. Takenouti, The a.c. response of RRDE during the passivation of iron, Corros. Sci., 31 (1990) 627-635.

[20] M. Itagaki, M. Tagaki, K. Watanabe, Active dissolution mechanisms of iron using EIS with channel flow double electrode. Influences of chloride and fluoride ions, Electrochim. Acta, 41 (1996) 1201-1207.

[21] G. Wittstock, M. Burchardt, S.E. Pust, Y. Shen, C. Zhao, Scanning electrochemical microscopy for direct imaging of reaction rates, Angew. Chem. Int. Ed., 46 (2007) 15841617.

[22] S. Amemiya, A.J. Bard, F.R.F. Fan, M.V. Mirkin, P.R. Unwin, Scanning Electrochemical Microscopy, in: Annual Review of Analytical Chemistry, vol. 1, 2008, pp. $95-131$.

[23] M.B. Jensen, D.E. Tallman, Application of SECM to corrosion studies, Electroanal. Chem., 24 (2012) 171-286.

[24] N. Casillas, S.J. Charlebois, W.H. Smyrl, H.S. White, Scanning electrochemical microscopy of precursor sites for pitting corrosion on titanium, J. Electrochem. Soc., 140 (1993) L142-L145.

[25] N. Casillas, S. Charlebois, W.H. Smyrl, H.S. White, Pitting Corrosion of Titanium, J. Electrochem. Soc., 141 (1994) 636-642. 
[26] M.B. Jensen, A. Guerard, D.E. Tallman, G.P. Bierwagen, Studies of electron transfer at aluminum alloy surfaces by scanning electrochemical microscopy, J. Electrochem. Soc., 155 (2008) C324-C332.

[27] C. Gabrielli, S. Joiret, M. Keddam, H. Perrot, N. Portail, P. Rousseau, V. Vivier, Development of a Coupled SECM-EQCM Technique for the Study of Pitting Corrosion on Iron, J. Electrochem. Soc., 153 (2006) B68-B74.

[28] C. Gabrielli, S. Joiret, M. Keddam, H. Perrot, N. Portail, P. Rousseau, V. Vivier, A SECM assisted EQCM study of iron pitting, Electrochim. Acta, 52 (2007) 7706-7714.

[29] C. Gabrielli, S. Joiret, M. Keddam, N. Portail, P. Rousseau, V. Vivier, Single pit on iron generated by SECM, Electrochim. Acta, 53 (2008) 7539-7548.

[30] J. Rodriguez-Lopez, M.A. Alpuche-Aviles, A.J. Bard, Interrogation of Surfaces for the Quantification of Adsorbed Species on Electrodes: Oxygen on Gold and Platinum in Neutral Media, J. Am. Chem. Soc., 130 (2008) 16985-16995.

[31] Q. Wang, J. Rodriguez-Lopez, A.J. Bard, Reaction of Br2 with Adsorbed CO on Pt, Studied by the Surface Interrogation Mode of Scanning Electrochemical Microscopy, J. Am. Chem. Soc., 131 (2009) 17046-17047.

[32] J. Rodriguez-Lopez, A. Minguzzi, A.J. Bard, Reaction of various reductants with oxide films on Pt electrodes as studied by the surface interrogation mode of scanning electrochemical microscopy (SI-SECM): Possible validity of a Marcus relationship, J. Phys. Chem. C, 114 (2010) 18645-18655.

[33] D. Trinh, M. Keddam, X.R. Novoa, V. Vivier, Alternating-Current Measurements in Scanning Electrochemical Microscopy, Part 1: Principle and Theory, ChemPhysChem, $12(2011)$ 2169-2176. 
[34] D. Trinh, M. Keddam, X.R. Novoa, V. Vivier, Alternating Current Measurements in Scanning Electrochemical Microscopy, Part 2: Detection of Adsorbates, ChemPhysChem, 12 (2011) 2177-2183.

[35] N. Garcia-Araez, V. Climent, E. Herrero, J.M. Feliu, On the electrochemical behavior of the Pt(100) vicinal surfaces in bromide solutions, Surf. Sci., 560 (2004) 269284.

[36] N. Garcia-Araez, V. Climent, E. Herrero, J. Feliu, J. Lipkowski, Thermodynamic studies of chloride adsorption at the $\mathrm{Pt}(111)$ electrode surface from $0.1 \mathrm{M} \mathrm{HClO} 4$ Solution, J. Electroanal. Chem., 576 (2005) 33-41.

[37] N. Garcia-Araez, J.J. Lukkien, M.T.M. Koper, J.M. Feliu, Competitive adsorption of hydrogen and bromide on $\operatorname{Pt}(100)$ : Mean-field approximation vs. Monte Carlo simulations, J. Electroanal. Chem., 588 (2006) 1-14.

[38] C. Gabrielli, E. Ostermann, H. Perrot, V. Vivier, L. Beitone, C. Mace, Concentration mapping around copper microelectrodes studied by scanning electrochemical microscopy, Electrochem. Commun., 7 (2005) 962-968.

[39] C. Gabrielli, M. Keddam, N. Portail, P. Rousseau, H. Takenouti, V. Vivier, Electrochemical Impedance Spectroscopy Investigations of a Microelectrode Behavior in a Thin-Layer Cell: Experimental and Theoretical Studies, J. Phys. Chem. B, 110 (2006) 20478-20485.

[40] C. Gabrielli, M. Keddam, H. Takenouti, Potential distribution at the surface of a ring-disk electrode, J. Chim. Phys. PCB, 69 (1972) 737-740.

[41] S. Ferro, A. De Battisti, The Bromine Electrode. Part I: Adsorption Phenomena at Polycrystalline Platinum Electrodes, J. Appl. Electrochem., 34 (2004) 981-987. 
[42] G.N. Salaita, D.A. Stern, F. Lu, H. Baltruschat, B.C. Schardt, J.L. Stickney, M.P. Soriaga, D.G. Frank, A.T. Hubbard, Structure and composition of a Platinum(111) surface as a function of $\mathrm{pH}$ and electrode potential in aqueous bromide solutions, Langmuir, 2 (1986) 828-835. [43] S. Ferro, C. Orsan, A. De Battisti, The bromine electrode Part II: reaction kinetics at polycrystalline Pt, J. Appl. Electrochem., 35 (2005) 273-278. [44] M. Keddam, H. Takenouti, Mechanism of anodic dissolution of iron in acid solution, CR Acad. Sci. II C, 270 (1970) 283-286. [45] J.O.M. Bockris, D. Drazic, A.R. Despic, The electrode kinetics of the deposition and dissolution of iron, Electrochim. Acta, 4 (1961) 325-361. [46] K.E. Heusler, Der Einfluß der Wasserstof fionenkonzentration auf das elektrochemische Verhalten des aktiven Eisens in sauren Lösungen, Z. Elektrochem., 62 (1958) $582-587$. 
Figure 1: Complex experimental collection efficiency for a $50 \mathrm{mM} \mathrm{Fe}(\mathrm{CN})_{6}^{3-}+0.5 \mathrm{M}$ $\mathrm{KCl}$ solution with the tip-to-substrate distance as a parameter. The tip was a $\mathrm{Pt}$ microelectrode, $20 \mu \mathrm{m}$ in diameter, biased at $0.745 \mathrm{~V} / \mathrm{SHE}$ and the Pt substrate at 0.465 $\mathrm{V} / \mathrm{SHE}$

Figure 2: Schematic representation of a monolayer of hydrogen adsorbed on platinum (a) and the competitive adsorption between hydrogen and bromine on platinum (b).

Figure 3: Cyclic voltammogram of the polycrystalline platinum electrode $(0.5 \mathrm{~cm}$ in diameter) in a $5 \mathrm{mM} \mathrm{KBr}+0.1 \mathrm{M} \mathrm{HClO}_{4}$ solution - initial potential $0.445 \mathrm{~V} / \mathrm{SHE}-5$ cycles at $50 \mathrm{mVs}^{-1}$.

Figure 4: Differential capacitances calculated from the complex experimental collection efficiency according to Eq. (5) $E_{\text {sub }}=-0.005 \mathrm{~V} / \mathrm{SHE}$, Pt-tip: $20 \mu \mathrm{m}$ in radius, Pt-substrate Figure 5: Electrochemical impedance diagrams of pure iron in sulfuric acid solution $(0.5$ M) as a function of the electrode potential.

Figure 6: Simulated electrochemical impedance diagrams for pure iron in sulfuric acid solution as a function of the electrode potential using Refs. [1, 2] for the choice of kinetic constants. (a) Bockris' mechanism: $k_{1}=0.4 \cdot 10^{6} e^{b_{1} \cdot E} ; b_{1}=38.4 \mathrm{~V}^{-1} ; k_{2}=8 \cdot 10^{-4} e^{b_{2} \cdot E}$; $b_{2}=7 \mathrm{~V}^{-1} ; \quad \beta=10^{-8} \mathrm{~mol} \cdot \mathrm{cm}^{-2} ; C_{d}=100 \mu \mathrm{F}$ (b) Heusler's mechanism: $k_{1}=10 e^{b_{1} \cdot E}$; 
$1 \quad b_{1}=19.2 \mathrm{~V}^{-1} ; \quad k_{-1}=15 \cdot 10^{-18} e^{-b_{-1} \cdot E} ; \quad b_{-1}=19.2 \mathrm{~V}^{-1} ; k_{2}=8 \cdot 10^{-4} e^{b_{2} \cdot E} ; \quad b_{2}=7 \mathrm{~V}^{-1}$

$2 \quad \beta=10^{-8} \mathrm{~mol} \cdot \mathrm{cm}^{-2} ; C_{d}=100 \mu \mathrm{F}$.

$3 \quad$ Figure 7: Simulated collection efficiency of the substrate for pure iron in sulfuric acid 4 solution as a function of the electrode potential (same kinetic constants as in Fig. 6). (a) 5 Bockris' mechanism, (b) Heusler's mechanism.

$6 \quad$ Figure 8: Experimental collection efficiency of the substrate for pure iron in sulfuric acid 7 solution $(0.5 \mathrm{M})$ as a function of the electrode potential.

9 Table 1: Capacitance, charge and time constant of the adsorption processes for the 10 different experiments performed. 
Figure 1

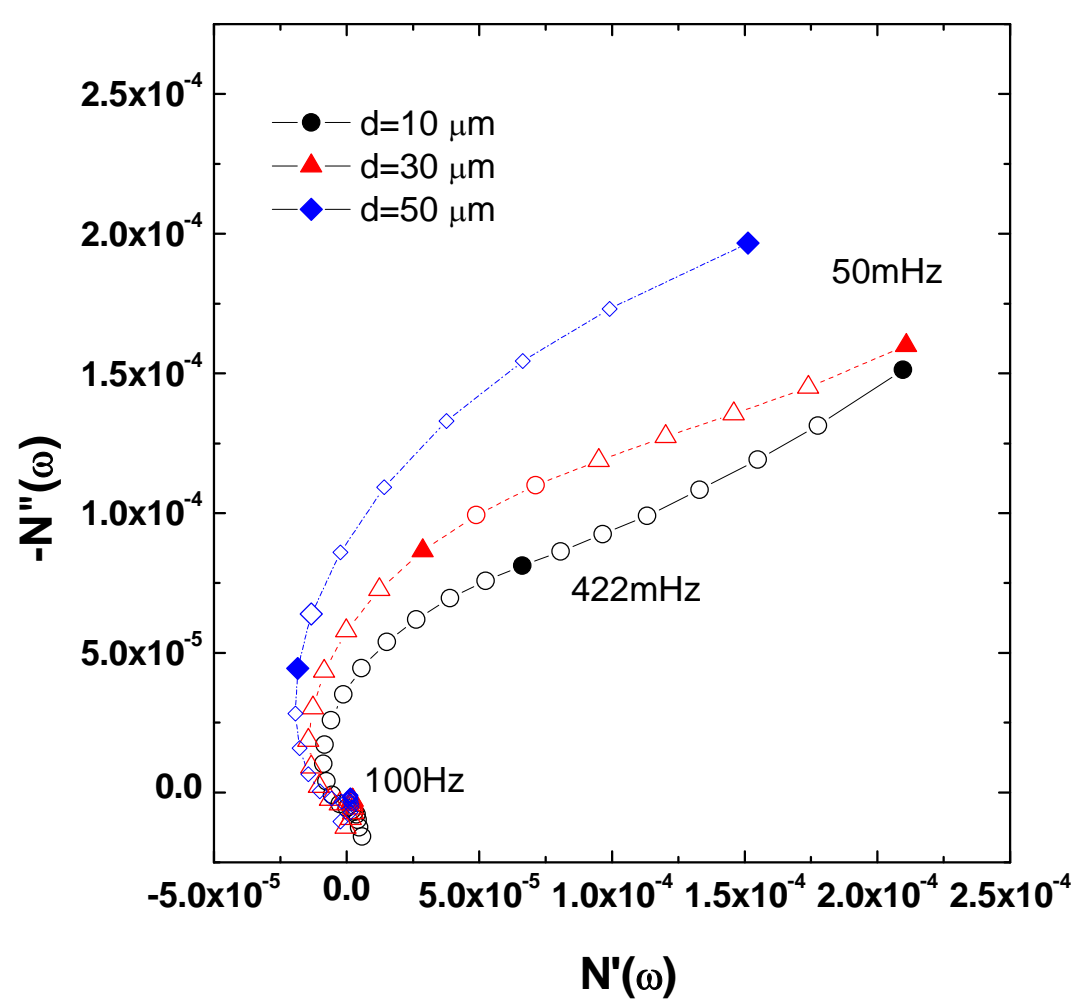

2

3

4 
1
2

Figure 2

3

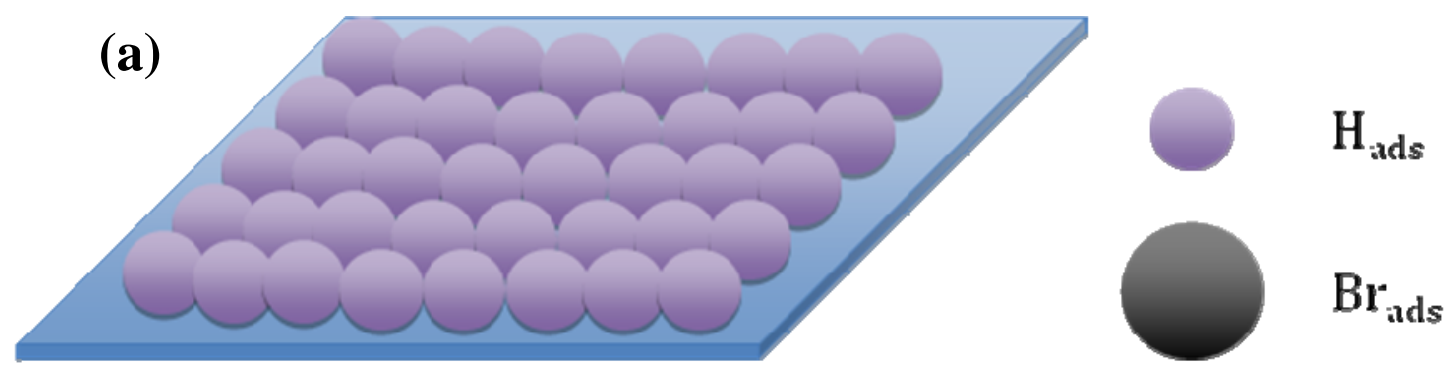

4

(b)

5

6
7

8 
Figure 3

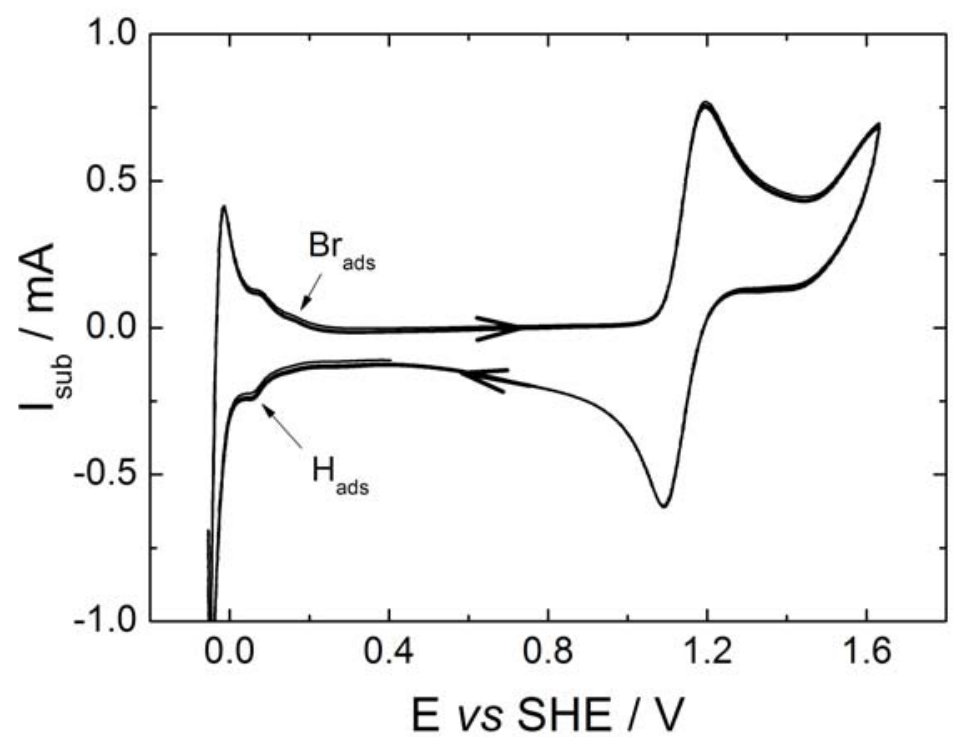


Figure 4

3

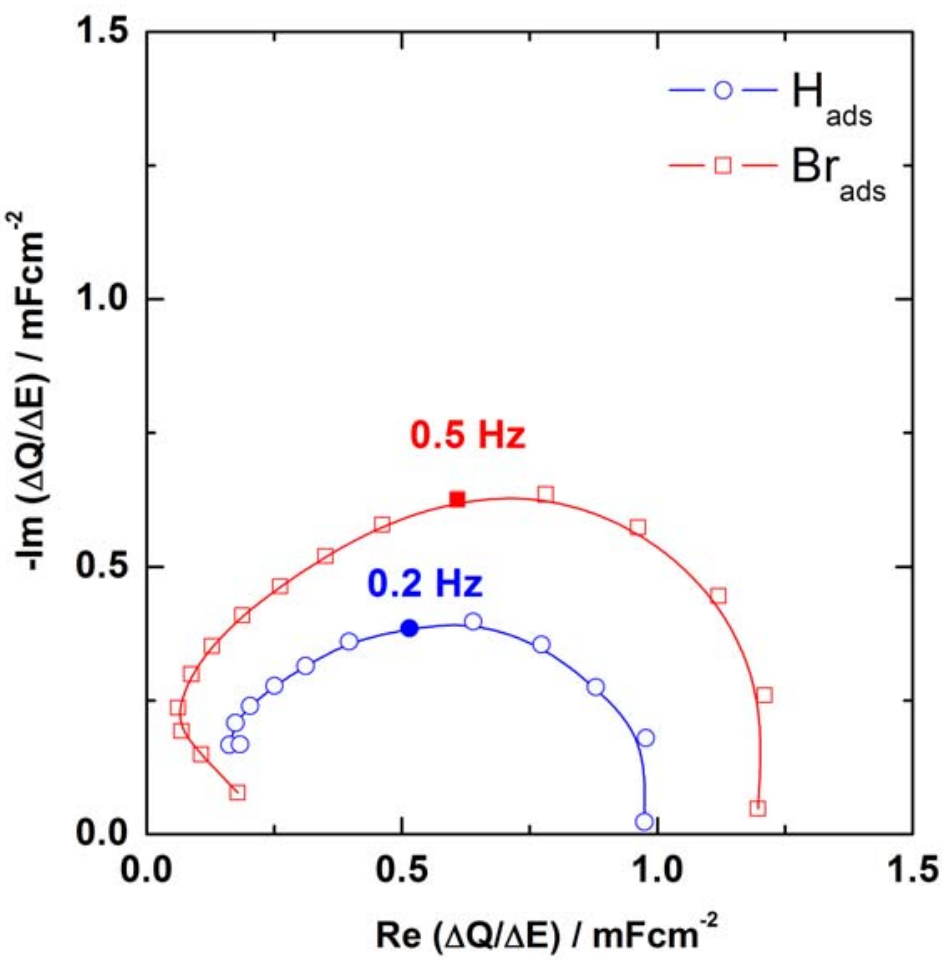

5 

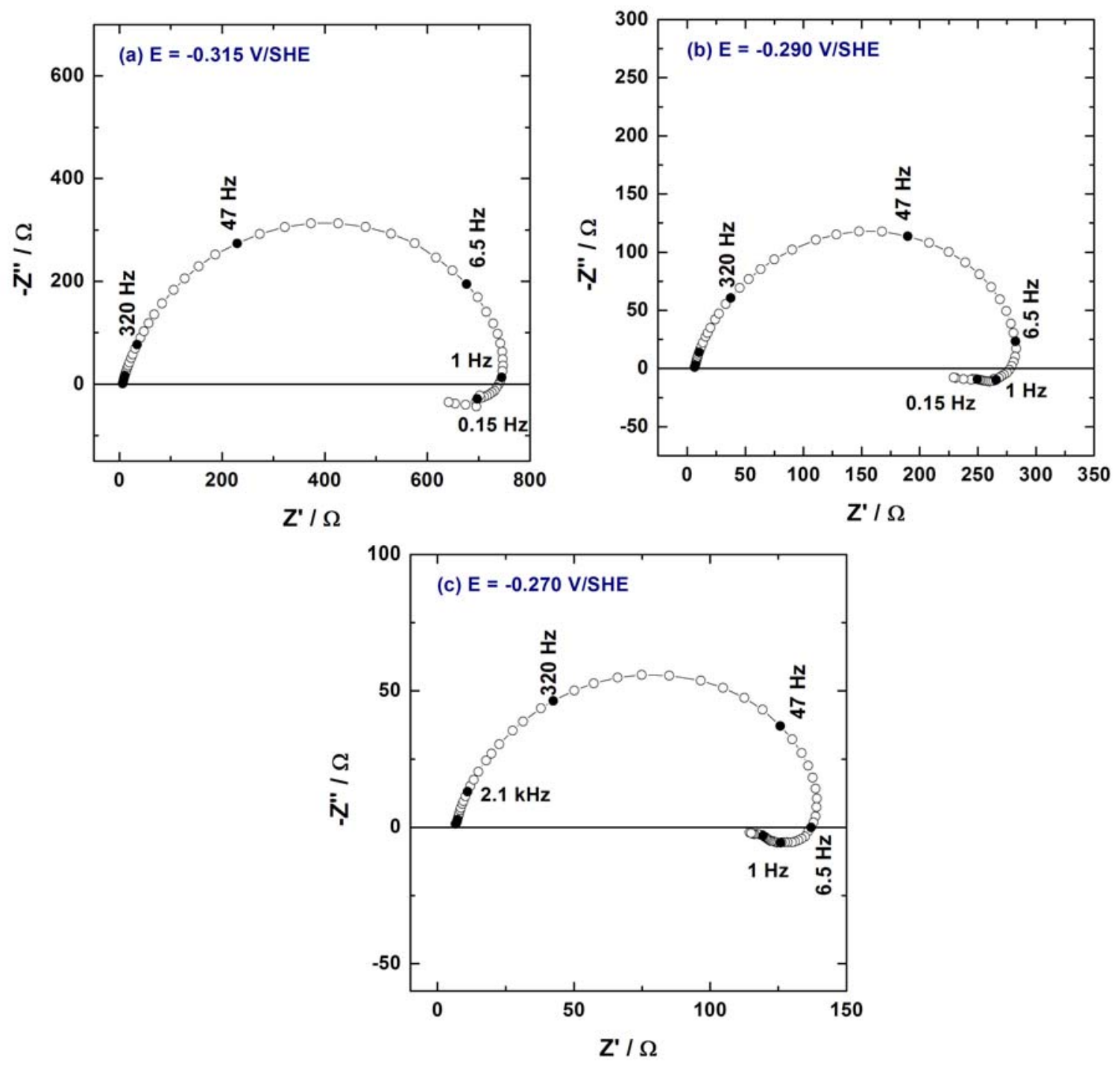

4
5 
2
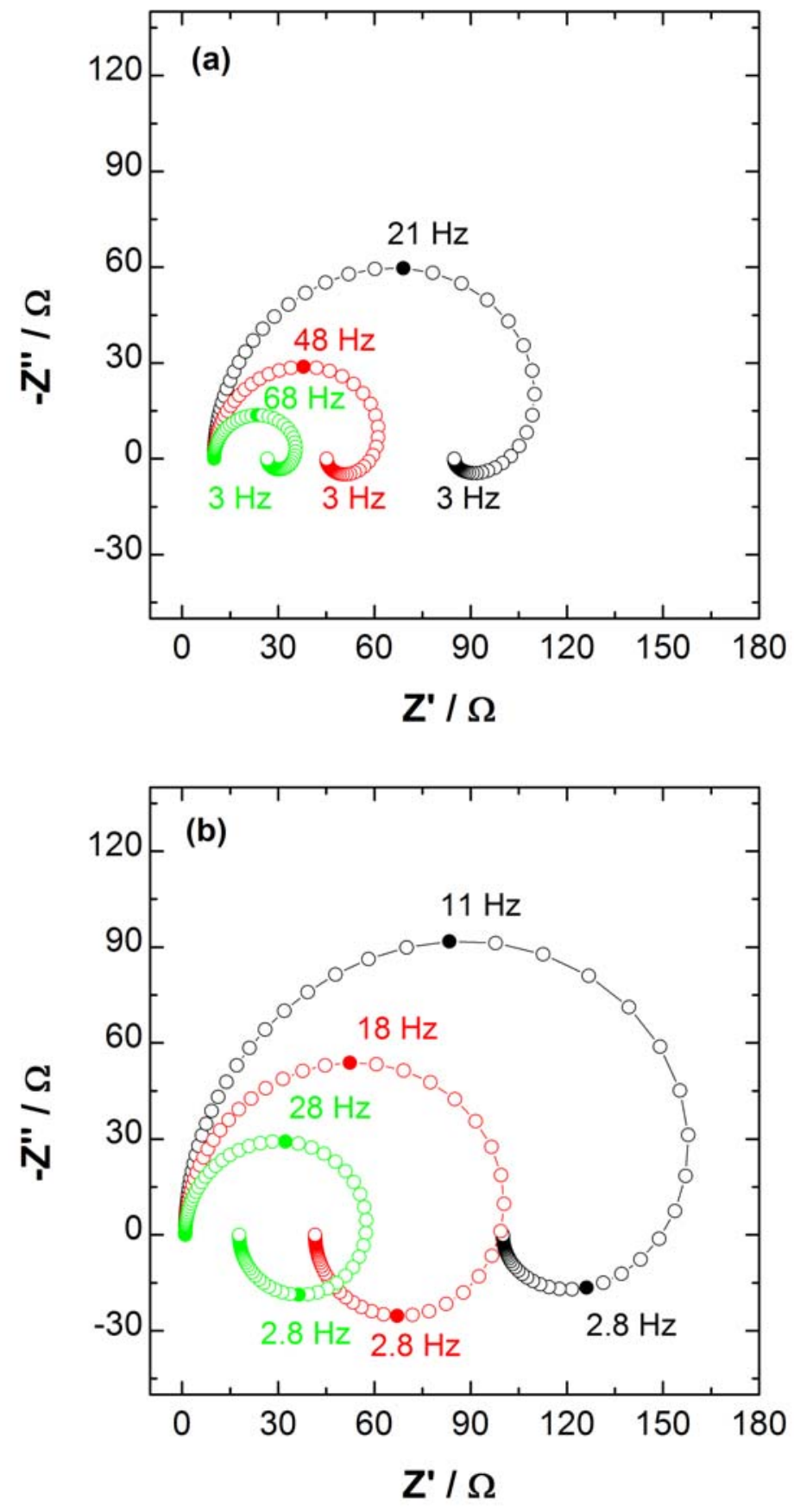

3
4 

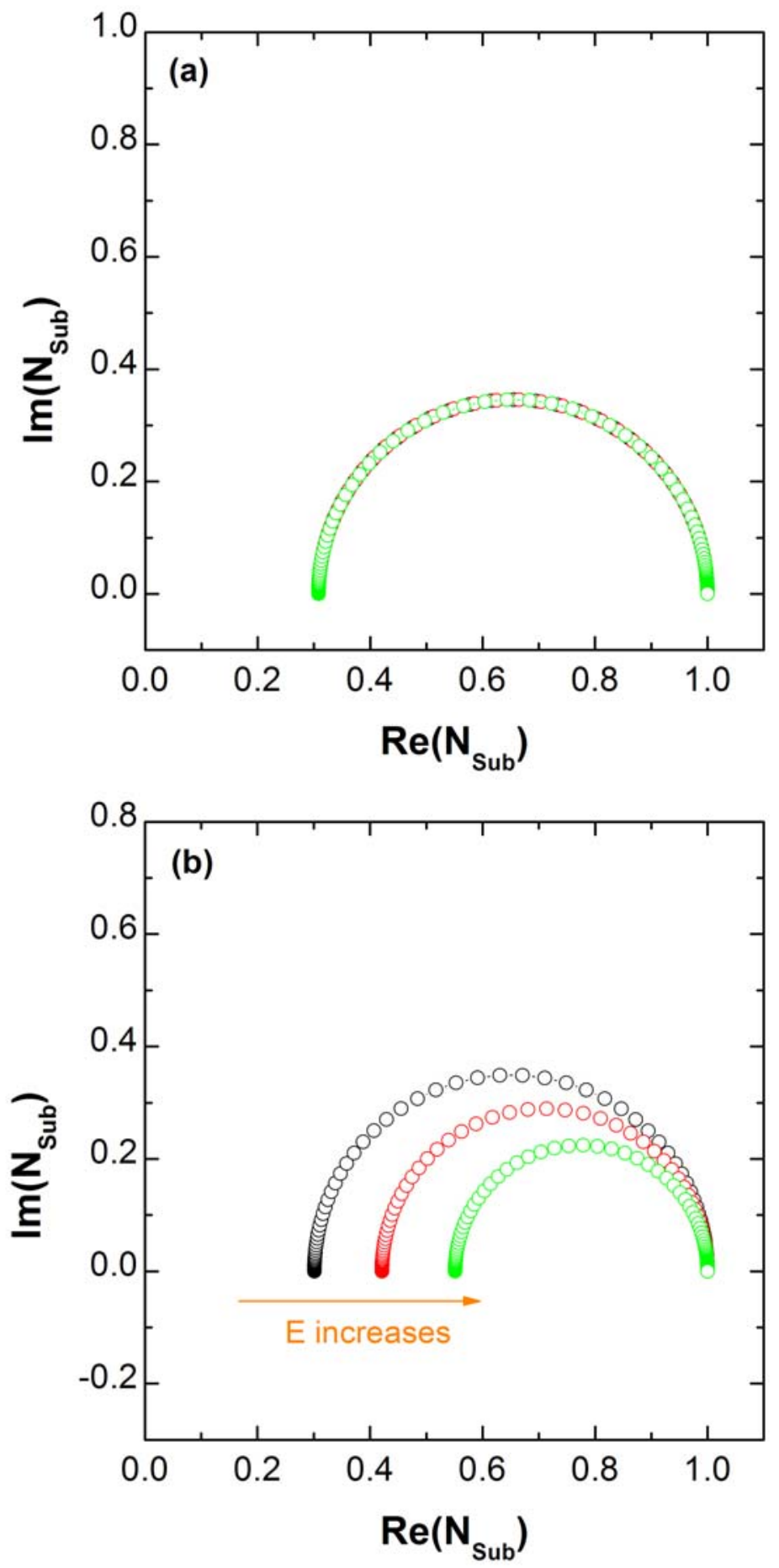
Figure 8

2

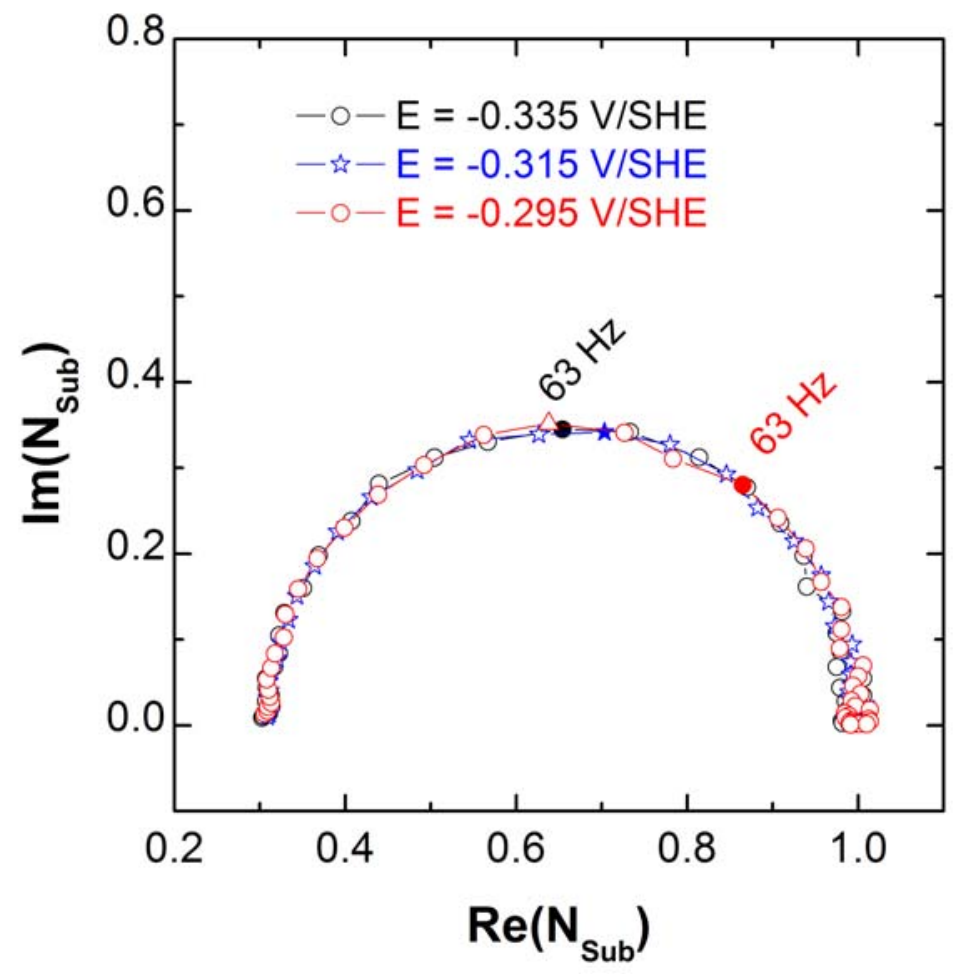

3
4 
3

4

\begin{tabular}{|c|c|c|c|}
\hline & $\begin{array}{c}\text { Capacitance } \\
/ \mathrm{mF} \mathrm{cm}^{-2}\end{array}$ & $\begin{array}{c}\text { Charge } \\
/ \mu \mathrm{cm}^{-2}\end{array}$ & $\begin{array}{c}\text { Characteristic } \\
\text { Frequency / Hz }\end{array}$ \\
\hline $\begin{array}{c}\text { Only } \mathrm{H}_{\text {ads }} \text { (without } \\
\text { the presence of Br) }\end{array}$ & $\mathbf{3}$ & $\mathbf{2 1 2}$ & $\mathbf{2}$ \\
\hline $\begin{array}{c}\mathrm{H}_{\text {ads }} \text { competitive } \\
\text { with } \mathrm{Br}_{\text {ads }}\end{array}$ & $\mathbf{1}$ & 71 & 0.2 \\
\hline $\begin{array}{c}\mathrm{Br}_{\text {ads }} \text { competitive } \\
\text { with } \mathrm{H}_{\text {ads }}\end{array}$ & $\mathbf{1 . 2}$ & $\mathbf{8 5}$ & 0.5 \\
\hline
\end{tabular}

5

6

7 